DOI: https://doi.org/10.36502/2020/droa.6174

\title{
Blood Glucose and Insulin Values on Daily Profile, M Value and Meal Tolerance in Patients with Type 2 Diabetes Mellitus (T2DM)
}

\author{
Takehisa $\mathrm{Y}^{1}$, Bando $\mathrm{H}^{2^{*}}$ \\ ${ }^{1}$ Hakuai Memorial Hospital, Heisei Medical Welfare (HMW) group, Tokushima, Japan \\ ${ }^{2}$ Tokushima University / Medical Research, Tokushima, Japan
}

Corresponding Author: Hiroshi BANDO, MD, PhD, FACP ${ }^{\text {ORCID iD }}$

Address: Tokushima University /Medical Research, Nakashowa 1-61, Tokushima 770-o943 Japan.

Received date: 05 December 2020; Accepted date: 24 December 2020; Published date: 31 December 2020

Citation: Takehisa Y, Bando H. Blood Glucose and Insulin Values on Daily Profile, M Value and Meal Tolerance in Patients with Type 2 Diabetes Mellitus (T2DM). Diab Res Open Access. 2020 Dec 31;2(3):85-94.

Copyright (c) 2020 Takehisa Y, Bando H. This is an open-access article distributed under the Creative Commons Attribution License, which permits unrestricted use, distribution, and reproduction in any medium, provided the original work is properly cited.

\begin{abstract}
Background: Authors and collaborators have continued medical practice in the Heisei Medical Welfare (HMW) group for long years for mainly two areas, extensive care for the elderly and diabetes research. From both of them, the current research was held on the daily profile of glucose and insulin for patients with type 2 diabetes mellitus (T2DM).

Subjects and Methods: Cases were 6 T2DM patients in admission, with ages $67.5 \pm 12.7$ years, diabetes duration 9.5 years. Methods included a daily profile of glucose and insulin for seven times per day, Morbus (M) value, Meal Tolerance Test (MTT) using breakfast with $70 g$ carbohydrate, insulinogenic index (IGI)-2 hours, various correlations among HbA1c, M value, Area Under the Curve (AUC) of glucose and insulin.

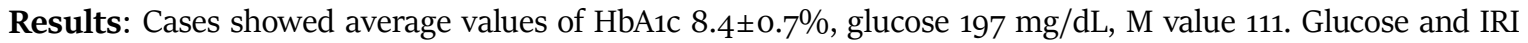
levels increased during $0700-0900 \mathrm{~h}$ with $154-258 \mathrm{mg} / \mathrm{dL}$ and $13.8-54.3 \mu \mathrm{U} / \mathrm{ml}$. There was a significant correlation between Glucose- $\triangle \mathrm{AUC}$ and $\mathrm{M}$ value $(\mathrm{p}<0.05)$.

Discussion: Daily profile of glucose and insulin showed a similar manner, suggesting post-prandial glucose influence due to carbohydrate intake. When studied cases increase, significant correlations among $\mathrm{M}$ value, HbA1c and glucose-AUC seem to be found. This report hopefully becomes a reference for future diabetic research.
\end{abstract}

\section{Keywords}

Daily Profile of Blood Glucose and Insulin, Meal Tolerance Test (MTT), Insulinogenic Index (IGI), Area Under the Curve (AUC), Morbus (M) Value, Heisei Medical Welfare (HMW)

\section{Introduction}

Diabetes is known to be one of the crucial noncommunicable diseases (NCDs) across the world and has given various influences socially and medically [1]. It may cause not only microangiopathy involving neuropathy, retinopathy, nephropathy but also macroangiopathy in the brain, heart, legs [2]. There are some standard guidelines for diabetes. One is the 2019 "Consensus Statement by the American Association of Clinical Endocrinologists (AACE) and American College of Endocrinology (ACE) on the Comprehensive Type 2 Diabetes Management Algorithm" [3], and another is the American Diabetes Association (ADA) Standards of Medical Care in 
Diabetes-2020 [4].

From the viewpoint of glucose variability, there is a concept of glucose ranges and targets [5]. The ideal target range has been indicated the international consensus on time in range (TIR). It has been provided from the detailed investigation of continuous glucose monitoring (CGM) metrics and considerations from the clinical interpretation and care [6]. In order to develop these metrics, there are some standardized reports recommending a visual manual with the ambulatory glucose profile (AGP) [6]. Various data from these analyses may help both the provider and patient to bring adequate treatment decisions. Consequently, this progress can result in diabetes management more useful for nutrition therapy, physical activity, preventing hypoglycemia, adjusting medications [7].

The authors and collaborators have been involved in two areas, diabetes research and extensive care research for the elderly. Firstly, authors and collaborators have continued medical practice for years in the Heisei Medical Welfare (HMW) group, which has been one of an international medical organization [8]. Specifically, in Japan, there are complex medical facilities in Tokushima, Tokyo, and other cities, as well as rehabilitation facilities in Indonesia, associated with more than 10,000 beds and 15,000 medical staff [9]. The philosophy and purpose of HMW would be to save all people, by providing proper acute care (PAC) and sub-acute care (SAC). A variety of patients have a wide range of health problems such as non-communicable diseases (NCD), diabetes mellitus, hypertension, dyslipidemia, chronic renal diseases (CKD), frailty syndrome in the elderly, and dementia. We have also reported on the practice of integrative medicine with music therapy as a wide range of medical care $[10,11]$.

Secondly, for diabetes, we have already reported diurnal fluctuations in blood glucose [12,13]. Among them, comparative studies of calorie restriction (CR) and low carbohydrate diet (LCD) have been conducted $[13,14]$. When changing the meal from CR to LCD, the daily profile of glucose drops dramatically from that day $[13,15]$. Among them, we have reported on clinical investigations, especially for diabetic patients $[9,16]$.
The authors have recently conducted studies on glycemic and insulin secretory dynamics from a pathophysiological aspect for meal tolerance test (MTT) in diabetic patients [17-19]. For this aspect, the dynamics of blood glucose and insulin on the diurnal variation of the day were investigated, with the estimation of a useful biomarker as Morbus (M) value $[17,20]$.

In our broad clinical practices mentioned above, our research group has now investigated the daily profiles of glycemic and insulin values with pre- and postprandial status in diabetic patients. In this article, we will report the results of the study and give some discussion.

\section{Subjects and Methods \\ Subjects}

Subjects in this study included six patients with T2DM in the admission of Hakuai Memorial Hospital, Tokushima, Japan. The background of the subjects is summarized and shown in Table-1.

\section{Methods}

There are some purposes and/or protocol of this study as follows: a) The daily profile of blood glucose and immunoreactive insulin (IRI) level were measured 7 times a day. They include pre-prandial and postprandial timings at three meals and night, b) From the changes of daily blood glucose, Morbus value was calculated that means the integral concept of elevated blood glucose in average and increased mean amplitude of glycemic excursions (MAGE), c) Meal Tolerance Test (MTT) was conducted using breakfast, which includes $70 \mathrm{~g}$ of carbohydrate from standard Japanese breakfast with rice, egg, fish, salad and miso soup, d) From the changes of blood glucose and IRI after 2 hours of breakfast, Insulinogenic Index (IGI) (2 hours) was calculated.

\section{AUC Study:}

For pathophysiological evaluation for glucose and IRI, the method of Area Under the Curve (AUC) has been used [21]. Glucose AUC can be measured and calculated by the multiplication of glucose value and time [22,23]. In the current study, data of glucose values are obtained 7 points from o70oh to $2100 h$, and 
the Glucose-AUC was calculated. Furthermore, we have also used Glucose-delta AUC (Glucose- $\triangle \mathrm{AUC}$ ). It means the incremental AUC from the point at 0700 AM, which equals total Glucose-AUC minus baselineAUC. Similarly, IRI-AUC and IRI-delta AUC (IRI- $\triangle$ AUC) were also calculated.

In our protocol of c) and d), we adopted and compared two methods. The former means the incremental values of glucose and IRI. It is expressed as Delta ratio of IGI for 2 hours, which can be calculated as (IRI at 2 hours - IRI at omin) ( $\mu \mathrm{U} / \mathrm{mL}) /$ (Glucose at 2 hours - Glucose at omin) (mg/dL)). The latter means the comparison of the total AUC of glucose and IRI. It is expressed as AUC Ratio of IGI for 2 hours, which can be calculated as (AUC-IRI for 0-2 hours) $(\mu \mathrm{U} / \mathrm{mL} \times \mathrm{h}) /$ (AUC-glucose for $0-2$ hours) (mg/dL x h) [24].

\section{$M$ Value Study:}

In diabetology, Morbus (M) value is a useful biomarker for research of glucose variability. M value includes two valuable meaningful data. The first is the value of the average blood glucose a day, and the second is the width of the blood glucose fluctuation, which is known as the mean amplitude of glycemic excursions (MAGE) [25-27]. M value has both meanings and can evaluate the general degree of the glucose variability in the diurnal rhythm.

Consequently, the $\mathrm{M}$ value can be calculated as one numerical value including two valuable perspectives. The former is the level of increased glucose on average, and the latter is the degree of elevated swinging glucose of the variability. On applying the following mathematic method, the $\mathrm{M}$ value is calculated for the equation by the logarithmic transformation method. Concerning clinical significance, $M$ value means the degree of the increased deviated glucose from the ideal level of glucose variability in the glucose profile [26-28].

The method of calculation of $\mathrm{M}$ value includes three steps. The first is the fundamental equation, which is $\mathrm{M}=\mathrm{M}^{\mathrm{BS}}+\mathrm{M}^{\mathrm{W}}$. M value is described as the total value of $\mathrm{M}^{\mathrm{BS}}$ and also $\mathrm{M}^{\mathrm{W}}$. The second is the $\mathrm{M}^{\mathrm{W}}$, which can express (max blood glucose - min glucose)/20. The last one showed that $\mathrm{M}^{\mathrm{BS}}$ is the mean level of MBSBS. By summarizing these data into an equation, MBSBS is the individual M-value for each blood glucose, that is calculated as (absolute numerical value of $[10 \times \log$ (blood glucose level/120)] $)^{3}$ [26-28]. The numerical number 120 means that the ideal level of glucose may be about $120 \mathrm{mg} / \mathrm{dL}$.

Generally speaking, glucose variability has been estimated as the increased level of $M$ value. The obtained results of $\mathrm{M}$ value have been evaluated in the following: i) the usually standard normal range would be less than 180 , ii) the borderline width would be 180 and more than 180 plus less than 320 , and iii) abnormal range would be 320 and more than 320 .

$$
\text { M-value }=\frac{\Sigma}{N}\left|\mathrm{M} \frac{B S}{B S}\right|+\mathrm{W} / 20 \quad \text { where } \quad \mathrm{M} \frac{B S}{B S}=\left|10 \log \frac{P G}{120}\right|^{3}
$$

\section{Statistical Analysis:}

In the current study, the number of subjects was small $(n=6)$, which means the pilot study. Before analyzing the data, a fundamental investigation was conducted. Since all items have a statistically normal distribution, all analyses were subjected to the Pearson correlation test [29].

\section{Ethical Considerations:}

The current study was basically performed along with the Declaration of Helsinki (revised at the 2013 WMA Fortaleza General Assembly). Further, the additional comment was performed along with the ethical guidelines for human-based medical research (notification by Ministry of Education, Culture, Sports, Science and Technology [MEXT] and Ministry of Health, Labour and Welfare [MHLW]). The content of the current test was fully explained to the patients in advance. We have obtained the written document agreements from all patients. This study was discussed in the ethical committee, where several professionals attended and approved, including physicians, nurses, pharmacists, nutritionists, and a person of legal specialty. This research has been registered and performed along with the National University Hospital Meeting (ID: \# Roooo34009). 


\section{Results}

In the current study, the results for 6 cases are shown in Table-1. Obtained levels of mean \pm standard deviation (SD) were as follows: ages $67.5 \pm 12.7$ years old (the median 64.5 yo., and $\mathrm{M} / \mathrm{F}=3 / 3$ ). Duration of diabetes is 9.5 years on average and 6.0 years in the median. HbA1c $8.4 \pm 0.7$ years (median 8.3\%). Regarding the average blood glucose from 7 -point measurement a day, the result showed $197 \mathrm{mg} / \mathrm{dL}$ on average ranging from $171.7 \mathrm{mg} / \mathrm{dL}$ to $233.3 \mathrm{mg} / \mathrm{dL}$. Furthermore, there were several results concerning glucose and insulin-related data were obtained.

The daily profile of glucose and IRI was shown in Fig-1. Blood glucose and IRI levels increased from o70oh to o9ooh, with 154 to $258 \mathrm{mg} / \mathrm{dL}$ and 13.8 to $54.3 \mu \mathrm{U} / \mathrm{ml}$ on average. From o9ooh to $2100 \mathrm{~h}$, both data were found to be moved in similar manner. Several kinds of correlations among HbA1c, M value, the AUC changes of blood glucose, and IRI were investigated (Fig-2). These results of the correlations between 2 factors are from a small number of cases $(n=6)$. There were 4 correlations shown as follows: a) correlation between $\mathrm{M}$ value and HbA1c is $\mathrm{p}=0.125$, not significant (Fig-2a), b) correlation between GlucoseAUC and HbAic is $\mathrm{p}=0.330$, not significant (Fig-2b), c) correlation between Glucose- $\triangle \mathrm{AUC}$ and $\mathrm{M}$ value is $\mathrm{p}=0.016$, significant $($ Fig-2c), d) correlation between IRI- $\triangle \mathrm{AUC}$ and Glucose- $\triangle \mathrm{AUC}$ is $\mathrm{p}=0.631$, not significant (Fig-2d).

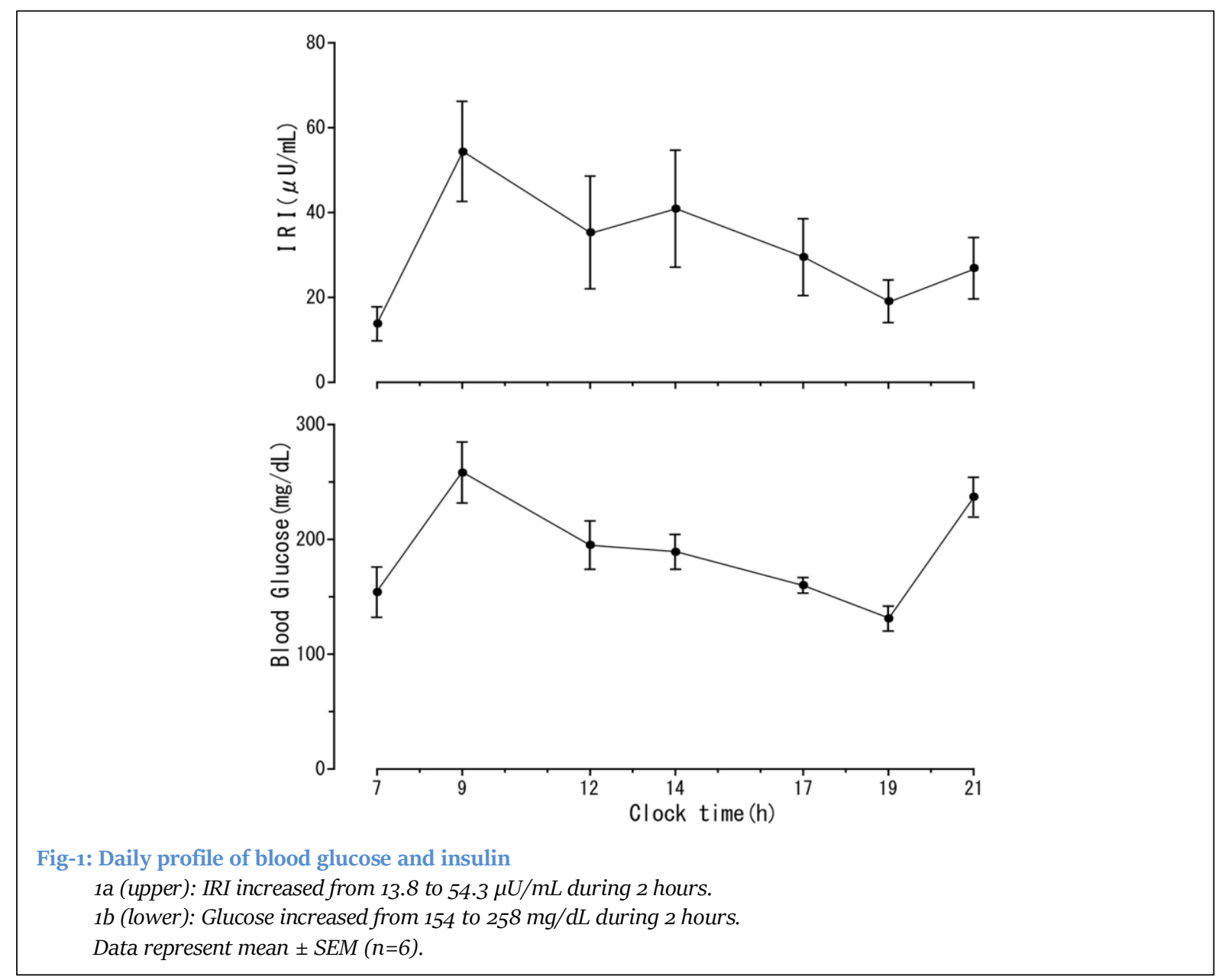

Further evaluation of the values of blood glucose and IRI during o70oh-ogooh was conducted. We investigated the relationship between the average glucose level and $\mathrm{M}$ value (Fig-3a) and between the IGI-delta method and IGI-AUC method (Fig-3b). The former revealed a close relationship (Fig-3a). For the latter, case D and F showed rather larger different data by two methods of calculation (Fig-3b). 
Citation: Takehisa Y, Bando H. Blood Glucose and Insulin Values on Daily Profile, M Value and Meal Tolerance in Patients with Type 2 Diabetes Mellitus (T2DM). Diab Res Open Access. 2020 Dec 31;2(3):85-94.

\section{Original Article}
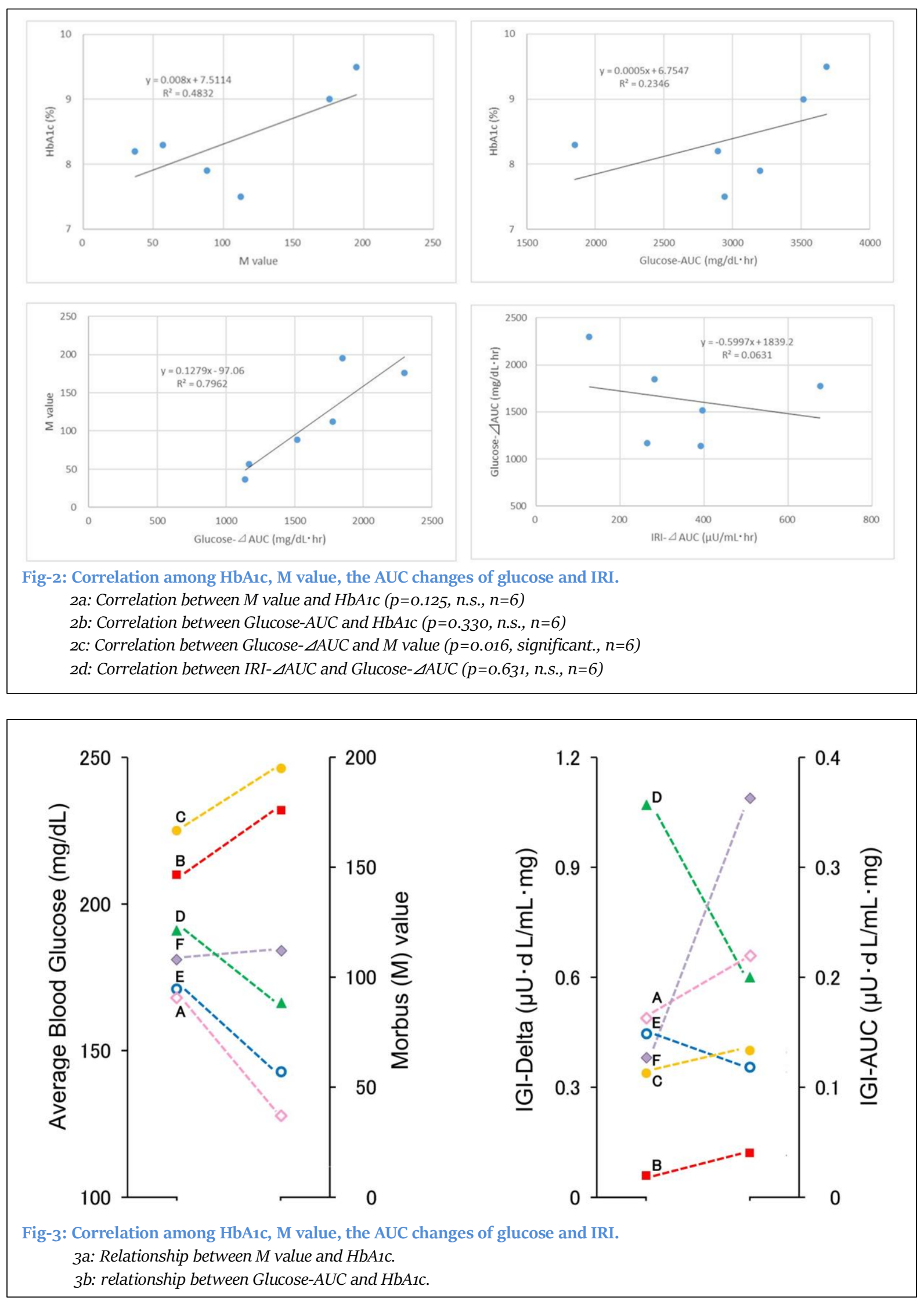


\section{Discussion}

In recent decades, the research on CR and LCD has expanded in the study of diabetes. LCD was advocated by Atkins and Bernstein and spread to Europe and the United States [30,31]. In Japan, Dr. Ebe in our research group had started LCD for the first time [32] and we have been enlightening how to practice petite-LCD, standard-LCD, and super-LCD [33].

$\mathrm{CR}$ includes higher carbohydrate and raises postprandial blood glucose [34]. On the other hand, LCD has lower carbohydrate and suppresses the rise in postprandial glucose [35]. In other words, it is important to reduce the response of postprandial glucose and insulin to meals [36]. Consequently, studies on diurnal fluctuations of glucose and insulin have been conducted. As a method, the pathophysiological status can be grasped by examining the AUC or $\triangle \mathrm{AUC}$ of glucose and insulin for 24 hours [37]. Studies on total AUC and $\triangle$ AUC for blood glucose and IRI in 0-3 hours were investigated after ingesting several foods [38]. With these research methods, detailed responses for glucose and insulin can be taken for various pathophysiological states.

In the current study, diurnal fluctuations in glucose and insulin levels were measured in 6 middle-aged and elderly diabetic patients. The correlations among mean blood glucose, HbA1c, $M$ value, AUC value, $\triangle \mathrm{AUC}$ value, etc. were investigated. Furthermore, AUC and $\triangle \mathrm{AUC}$ in glucose and insulin during o70oh and ogooh were measured and analyzed. Regarding the patient background, the mean HbA1c was $8.4 \%$ and the mean blood glucose was $197 \mathrm{mg} / \mathrm{dL}$. Then, these subjects were estimated to be in rather a moderate degree of diabetes mellitus (Table-1).

\begin{tabular}{|c|c|c|c|c|c|c|c|c|c|}
\hline \multicolumn{10}{|c|}{ Table-1: List of the Cases with Glucose Profile } \\
\hline \multicolumn{3}{|c|}{ Case } & \multirow{2}{*}{$\begin{array}{l}\text { HbAic } \\
\text { HbAic }\end{array}$} & \multicolumn{4}{|c|}{ Glucose related Profile } & \multicolumn{2}{|c|}{ Insulin Profile } \\
\hline \multirow{2}{*}{ Case } & \multirow{2}{*}{ Age/Sex } & DM Hx & & Glu-Ave & Glu-AUC & Glu- $\triangle \mathrm{AUC}$ & \multirow{2}{*}{$M$ value } & IRI-AUC & IRI- $\triangle A$ AUC \\
\hline & & (yr) & (\%) & $(\mathrm{mg} / \mathrm{dL})$ & $(\mathrm{mg} / \mathrm{dL} \cdot \mathrm{hr})$ & $(\mathrm{mg} / \mathrm{dL} \cdot \mathrm{hr})$ & & $(\mu \mathrm{U} / \mathrm{mL} \cdot \mathrm{hr})$ & $(\mu \mathrm{U} / \mathrm{mL} \cdot \mathrm{hr})$ \\
\hline A & $49 \mathrm{M}$ & 7 & 8.2 & 171.7 & 2892 & 1140 & 37 & 566 & 392 \\
\hline B & $83 \mathrm{M}$ & 27 & 9.0 & 217.0 & 3514 & 2300 & 176 & 176 & 126 \\
\hline $\mathrm{c}$ & $81 \mathrm{~F}$ & 1 & 9.5 & 233.3 & 3684 & 1848 & 195 & 468 & 282 \\
\hline D & $63 \mathrm{~F}$ & 4 & 7.9 & 194.8 & 3200 & 1520 & 88 & 514 & 396 \\
\hline $\mathrm{E}$ & $64 \mathrm{~F}$ & 5 & 8.3 & 177.3 & 1850 & $117 \mathrm{o}$ & 57 & 344 & 264 \\
\hline $\mathrm{F}$ & $65 \mathrm{M}$ & 13 & 7.5 & 187.7 & $294^{\circ}$ & 1776 & 112 & 1056 & 676 \\
\hline Average & 67.5 & 9.5 & 8.4 & 197.0 & 3180 & 1826 & 111 & 520.8 & 355.4 \\
\hline
\end{tabular}

The characteristic of diurnal variation in blood glucose and IRI seemed to be that the movements of both graphs are generally similar (Fig-1). For preprandial and post-prandial points of breakfast, glucose and IRI were clearly elevated. These results were observed in all 6 cases. One of the reasons may be the process that they had breakfast after persisting overnight fast. On the other hand, those cases did not show a constant tendency for lunch and supper. The reason has not been clarified, but some possibilities are suggested, such as the difference in the both of absorption and digestion, the content of the meal with $\mathrm{PFC}$ ratio, the influence of breakfast to lunch including second meal phenomenon.

Among them, an increase in glucose and IRI has been found from 1900 to 2100 at night. The reason for this is not clear, but glucose and insulin responses may differ between morning and night. Concerning this phenomenon, there was a recent report by Leung et al. [39]. Biological results of eating habits at night would be responsible for increased postprandial glucose response, compared with that at an earlier time in the day. According to the investigation on electronic databases, primary outcome markers were post-prandial glucose and IRI area under the curve (AUC) or $\triangle A U C$ (incremental AUC, iAUC). This mechanism would lead to the well-known tendency that those who usually eat during the night apt to have a higher risk of metabolic situation including T2DM and cardiovascular disease (CVD) [39].

As regard to the detailed glucose fluctuation, there was rapid development due to CGM with new 
technology [6]. From these accumulated data, the provider can determine the time in range (TIR) with the assessment of hyperglycemia, hypoglycemia, and glycemic variability. The standard TIR shows very high (>250 mg/dL), high (181-250 $\mathrm{mg} / \mathrm{dL})$, target range (70-180 $\mathrm{mg} / \mathrm{dL})$, low (54-69 mg/dL), and very low ( $<54 \mathrm{mg} / \mathrm{dL}$ ). According to the published data, a strong correlation has been suggested between TIR and HbA1c value, such as a goal of $70 \%$ TIR aligning with an $\mathrm{HbA} 1 \mathrm{c}$ of $7 \%$ from two prospective investigations $[7,40]$. A detailed study of glucose and insulin values would be expected for future study.

In the current report, several correlations were studied among HbA1c, $M$ value, the AUC changes in blood glucose, and IRI (Fig-2a to Fig-2d). There was a significant correlation between Glucose- $\triangle \mathrm{AUC}$ and $\mathrm{M}$ value (Fig-2C). In contrast, there was not a significant correlation between $\mathrm{M}$ value and $\mathrm{HbA1c}$, and between Glucose-AUC and HbA1c (Fig-2a and Fig-2b). Current statistical studies have a small sample number $(n=6)$, then they will presumably show significant correlations with a sufficient numerical number of subjects. In the research for the glucose variability, some biomarkers such as HbA1c, M value, AUC, and $\triangle \mathrm{AUC}$ (incremental AUC, iAUC) seem to be useful for investigating various correlations.

Regarding the relationship between blood glucose level and insulin secretion, the insulinogenic index (IGI) for $75 \mathrm{~g}$ OGTT has been prevalent for years $[41,42]$. Adjunct to the studies of CR and LCD, authors have proposed and studied IGI-carbo70 because the breakfast of the $\mathrm{CR}$ diet contains carbohydrate $70 \mathrm{~g}$ [43]. Furthermore, we have tried research methods using C-peptide values instead of insulin as a biomarker and reported clinical usefulness [44].

Concerning the analysis of the meal tolerance test (MTT), the time period was not $0-30 \mathrm{~min}$ as a conventional method but $0-2$ hours as a pilot study [14-16]. The result showed the intersection of case D and case F (Fig-3b), where the relative difference seemed to exist between the total area of IGI and the area of $\Delta$ IGI. In previous studies, elder patients tended to show slower glucose and IRI responses with higher IRI values and glucose 2 hours after a meal [24].
Therefore, we analyzed AUC and $\triangle \mathrm{AUC}$ for glucose and IRI during $\mathrm{o}-2 \mathrm{~h}$ and analyzed several related data [23]. The result showed that the obtained distribution of $\mathrm{M}$ value was wider than the distribution of mean blood glucose, and then the difference can be clearly grasped [24]. In this way, even if the levels of HbA1c and mean blood glucose are nearly the same in many diabetic cases, the $\mathrm{M}$ value level could be clinically useful for detecting unstable glucose variability such as larger MAGE [17].

There are some limits to this study, and the following factors can be considered. Those are i) the number of cases is small, ii) both glucose and IRI are measured seven times per day, which are not sufficient times, iii) other possible influencing biomarkers are not measured at the same time. From this pilot study, it is positive and significant to obtain the theme or direction for the research in the future.

In summary, the diurnal variation of both glucose and insulin was measured against diabetic patients. Their AUC and $\triangle$ AUC were calculated and obtained from the data, and the relationship among some biomarkers was investigated. This research will be hopefully served as reference data for research development in the future.

\section{Acknowledgment}

The authors would like to express our gratitude for related all people concerning this research.

\section{Funding}

This work has not been funded by any institution or organization.

\section{Conflict of Interest}

All authors have read and approved the final version of the manuscript. The authors have no conflicts of interest to declare.

\section{References}

[1] IDF Diabetes Atlas 9th edition 2019. Available from: https://diabetesatlas.org/

[2] Mauricio D, Alonso N, Gratacòs M. Chronic Diabetes Complications: The Need to Move beyond Classical [PMID: 32033865] 
[3] Garber AJ, Abrahamson MJ, Barzilay JI, Blonde L, Bloomgarden ZT, Bush MA, Dagogo-Jack S, DeFronzo RA, Einhorn D, Fonseca VA, Garber JR, Garvey WT, Grunberger G, Handelsman Y, Hirsch IB, Jellinger PS, McGill JB, Mechanick JI, Rosenblit PD, Umpierrez GE. Consensus statement by the American Association of Clinical Endocrinologists and American College of Endocrinology on the comprehensive type 2 diabetes management algorithm: 2019 executive summary. Endocr Pract. 2019 Jan;25(1):69-100. [PMID: 30742570]

[4] American Diabetes Association. 9. Pharmacologic Approaches to Glycemic Treatment: Standards of Medical Care in Diabetes-2020. Diabetes Care. 2020 Jan;43(Suppl 1):S98-110. [PMID: 31862752]

[5] American Diabetes Association. 6. Glycemic Targets: Standards of Medical Care in Diabetes-2020. Diabetes Care. 2020 Jan;43(Suppl 1):S66-76. [PMID: 31862749]

[6] Battelino T, Danne T, Bergenstal RM, Amiel SA, Beck R, Biester T, Bosi E, Buckingham BA, Cefalu WT, Close KL, Cobelli C, Dassau E, DeVries JH, Donaghue KC, Dovc K, Doyle FJ 3rd, Garg S, Grunberger G, Heller S, Heinemann L, Hirsch IB, Hovorka R, Jia W, Kordonouri O, Kovatchev B, Kowalski A, Laffel L, Levine B, Mayorov A, Mathieu C, Murphy HR, Nimri R, Nørgaard K, Parkin CG, Renard E, Rodbard D, Saboo B, Schatz D, Stoner K, Urakami T, Weinzimer SA, Phillip M. Clinical Targets for Continuous Glucose Monitoring Data Interpretation: Recommendations From the International Consensus on Time in Range. Diabetes Care. 2019 Aug;42(8):1593-603. [PMID: 31177185]

[7] Beck RW, Bergenstal RM, Cheng P, Kollman C, Carlson AL, Johnson ML, Rodbard D. The Relationships Between Time in Range, Hyperglycemia Metrics, and HbA1c. J Diabetes Sci Technol. 2019 Jul;13(4):614-26. [PMID: 30636519]

[8] Heisei Medical Welfare (HMW) group. Available From: https://hmw.gr.jp/

[9] Takehisa Y, Bando H. Elderly Diabetic Patients with Effective Add-on Therapy of Dulaglutide as a GLP-1 Receptor Analogue (GLP-1 RA). Edel J Biomed Res Rev. 2020 Sep 10;2(1):31-35.

[10] Bando H, Yoshioka A, Nishikiori Y. Various Care Option of Integrative Medicine from the Viewpoint of Patient-Oriented Medicine. Int J Conf Proc. 2020 Jan 10;2(1):000529.
[11] Nishikiori Y, Bando H, Yoshioka A, Fujita M, Kusaka Y, Yuu M, Takehisa Y. Trials of Additional Effective Movements for Music Therapy Session for the Elderly. Curr Res Complement Altern Med. 2020;4(1):138.

[12] Ebe K, Bando H, Muneta T, Bando M, Yonei Y. Homeostasis model assessment (HOMA) and M value in daily profile of glucose. POJ Clin Case Rep. 2018 Aug 14;1(1):1-7.

[13] Bando H, Muneta T, Bando M, Yonei Y. Effect of low carbohydrate diet on type 2 diabetic patients and usefulness of M-value. Diabetes Res Open J. 2017 Feb 13;3(1):9-16.

[14] Muneta T, Kawaguchi E, Hayashi M, Bando H, Ebe K. Rapid Efficacy of Low Carbohydrate Diet for Diabetic Patient by Use of FreeStyle Libre. Diabetes Case Rep. 2019 Jan 22;4(2):138.

[15] Ebe K, Bando H. New era of diet therapy and research including Low Carbohydrate Diet (LCD). Asp Biomed Clin Case Rep. 2018;2(s1):1-3.

[16] Shimizu E, Takehisa Y, Bando H, Fujita M, Kusaka Y, Yuu M. Effective SGLT2 Inhibitor for Patient with Type 2 Diabetes Mellitus (T2DM) and Depression. Diab Res Open Access. 2020 Apr 14;2(S1):26-32.

[17] Bando H, Ebe K, Muneta T, Bando M, Yonei Y. Evaluating pancreas function by meal tolerance test (MTT) in diabetes. American Journal of Diabetes Research. 2018 Jul 29;1(1):101-109.

[18] Ebe K, Hashimoto M, Bando H, Bando M, Muneta T. Proposal of Meal Tolerance Test (MTT) For Investigating Ability of Insulin Secretion for Small Carbohydrate Load. Diab Res Open Access. 2020 Jun 12;2(2):31-37.

[19] Hashimoto M, Ebe K, Bando H, Bando M, Muneta T. Response of insulin secretion to small amount of meal on low carbohydrate diet (LCD). Biomed Sci J. 2020;1:3

[20] Ebe K, Bando H, Muneta T, Bando M, Yonei Y. Homeostasis model assessment (HOMA) and M value in daily profile of glucose. POJ Clin Case Rep. 2018 Aug 14;1(1):1-7.

[21] Wolever TM. Effect of blood sampling schedule and method of calculating the area under the curve on validity and precision of glycaemic index values. Br J Nutr. 2004 Feb;91(2):295-301. [PMID: 14756916]

[22] Sakaguchi K, Takeda K, Maeda M, Ogawa W, Sato T, Okada S, Ohnishi Y, Nakajima H, Kashiwagi A. 
Glucose area under the curve during oral glucose tolerance test as an index of glucose intolerance. Diabetol Int. 2015 May 14;7(1):53-58. [PMID: 30603243]

[23] Safari S, Amini M, Aminorroaya A, Feizi A. Patterns of changes in fasting plasma glucose, hemoglobin A1c and the area under the curve during oral glucose tolerance tests in prediabetic subjects: results from a 16-year prospective cohort study among first-degree relatives of type 2 diabetic patients. Acta Diabetol. 2020 Oct 21. [PMID: 33084981]

[24] Bando H, Ebe K, Muneta T, Bando M, Yonei Y. Investigation of Area under the Curves for Insulin Secretion in Diabetes. Int J Biotechnol Recent Adv. 2018;1(1):24-29.

[25] Schlichtkrull J, Munck O, Jersild M. The M-value, an index of blood sugar control in diabetics. Acta Med Scand. 1965 Jan;177:95-102. [PMID: 1425186o]

[26] Service FJ, Molnar GD, Rosevear JW, Ackerman E, Gatewood LC, Taylor WF. Mean amplitude of glycemic excursions, a measure of diabetic instability. Diabetes. 1970 Sep;19(9):644-55. [PMID: 5469118]

[27] Molnar GD, Taylor WF, Ho MM. Day-to-day variation of continuously monitored glycaemia: a further measure of diabetic instability. Diabetologia. 1972 Nov;8(5):342-48. [PMID: 4641791]

[28] Moberg E, Kollind M, Lins PE, Adamson U. Estimation of blood-glucose variability in patients with insulin-dependent diabetes mellitus. Scand J Clin Lab Invest. 1993 Aug;53(5):507-14. [PMID: 8210974]

[29] Yanai H. Four step excel statistics. 4th ed. Tokyo: Seiun-sha Publishing Co. Ltd; 2015.

[30] Atkins R. Dr Atkins' New Diet Revolution. New York, NY: Harper Collins; 2002.

[31] Bernstein RK. Dr. Bernstein's diabetes solution: the complete guide to achieving normal blood sugars. New York, NY: Little, Brown; 2011 Nov 1.

[32] Ebe K, Ebe Y, Yokota S, Matsumoto T, Hashimoto M, Sakai Y. Low Carbohydrate diet (LCD) treated for three cases as diabetic diet therapy. Kyoto Medical Association Journal. 2004;51:125-29.

[33] Bando H, Ebe K, Muneta T, Bando M, Yonei Y. Clinical effect of low carbohydrate diet (LCD): Case report. Diabetes Case Rep. 2017 Jun 10;2(2):124.

[34] Japan Diabetes Association. Diabetes clinical practice guidelines Based on scientific evidence; 2013.

[35] Röhling M, Martin T, Wonnemann M, Kragl M,
Klein HH, Heinemann L, Martin S, Kempf K. Determination of Postprandial Glycemic Responses by Continuous Glucose Monitoring in a Real-World Setting. Nutrients. 2019 Sep 27;11(10):2305. [PMID: 31569815]

[36] Mela DJ, Cao XZ, Dobriyal R, Fowler MI, Lin L, Joshi M, Mulder TJP, Murray PG, Peters HPF, Vermeer MA, Zhang Z. The effect of 8 plant extracts and combinations on post-prandial blood glucose and insulin responses in healthy adults: a randomized controlled trial. Nutr Metab (Lond). 2020 Jul 6;17:51. [PMID: 32647531]

[37] Parr EB, Devlin BL, Radford BE, Hawley JA. A Delayed Morning and Earlier Evening Time-Restricted Feeding Protocol for Improving Glycemic Control and Dietary Adherence in Men with Overweight/Obesity: A Randomized Controlled Trial. Nutrients. 2020 Feb 17;12(2):505. [PMID: 32079327]

[38] Perraudeau F, McMurdie P, Bullard J, Cheng A, Cutcliffe C, Deo A, Eid J, Gines J, Iyer M, Justice N, Loo WT, Nemchek M, Schicklberger M, Souza M, Stoneburner B, Tyagi S, Kolterman O. Improvements to postprandial glucose control in subjects with type 2 diabetes: a multicenter, double blind, randomized placebo-controlled trial of a novel probiotic formulation. BMJ Open Diabetes Res Care. 2020 Jul;8(1):eoo1319. [PMID: 32675291]

[39] Leung GKW, Huggins CE, Ware RS, Bonham MP. Time of day difference in postprandial glucose and insulin responses: Systematic review and metaanalysis of acute postprandial studies. Chronobiol Int. 2020 Mar;37(3):311-26. [PMID: 31782659]

[40] Vigersky RA, McMahon C. The Relationship of Hemoglobin A1C to Time-in-Range in Patients with Diabetes. Diabetes Technol Ther. 2019 Feb;21(2):81-85. [PMID: 30575414]

[41] Hanson RL, Pratley RE, Bogardus C, Narayan KM, Roumain JM, Imperatore G, Fagot-Campagna A, Pettitt DJ, Bennett PH, Knowler WC. Evaluation of simple indices of insulin sensitivity and insulin secretion for use in epidemiologic studies. Am J Epidemiol. 2000 Jan 15;151(2):190-98. [PMID: 10645822]

[42] Matsuda M, DeFronzo RA. Insulin sensitivity indices obtained from oral glucose tolerance testing: comparison with the euglycemic insulin clamp. Diabetes Care. 1999 Sep;22(9):1462-70. [PMID: 10480510] 
Citation: Takehisa Y, Bando H. Blood Glucose and Insulin Values on Daily Profile, M Value and Meal Tolerance in Patients with Type 2 Diabetes Mellitus (T2DM). Diab Res Open Access. 2020 Dec 31;2(3):85-94.

\section{Original Article}

[43] Bando H, Ebe K, Muneta T, Bando M, Yonei Y. Proposal for insulinogenic index (IGI)-carbo7o as experimental evaluation for diabetes. J Clin Exp Endocrinol. 2017 Oct 18;1(1):102.

[44] Ebe K, Bando H, Muneta T, Bando M, Yonei Y. Investigation of C-peptide Index for Carbo70 by the severity of diabetic state. Clin Med Case Rep. 2018 Jul $16 ; 2(2): 113$.

Keywords: Daily Profile of Blood Glucose and Insulin, Meal Tolerance Test (MTT), Insulinogenic Index (IGI), Area Under the Curve (AUC), Morbus (M) Value, Heisei Medical Welfare (HMW) 